\title{
Students' Awareness of E-waste and Its Disposal Practices: a Conceptual Framework
}

Sultan Adeel ( $\square$ sultan.adeel@iba-suk.edu.pk)

Sukkur IBA University https://orcid.org/0000-0002-1100-5857

Anam Nayab

Sukkur IBA University

Moeez Ullah Qureshi

Sukkur IBA University

Khalil Ahmed Channa

Sukkur IBA University

\section{Research Article}

Keywords: E-waste awareness, E-waste disposal, monetary benefits, Sensitive information, Family sharing

Posted Date: February 25th, 2022

DOI: https://doi.org/10.21203/rs.3.rs-1395270/v1

License: (1) (1) This work is licensed under a Creative Commons Attribution 4.0 International License. Read Full License 


\section{Abstract}

An exponential increase in technology consumption at an individual level boosted e-waste generation. Pakistan is among a few countries generating and receiving enormous e-waste, thus positing a threat to our future generations. A review of recent studies also suggested a dire need to explore e-waste awareness and its disposal practices to design policies for avoiding the most likely threat to human and environmental health. To this end, we explored consumer awareness of e-waste and noticeable factors hindering the disposal of laptops, personal computers, and mobiles. The study used the qualitative research approach and non-probability sampling. We collected data through four Focus Group Discussions (FGDs) with students of a Pakistani university. After data saturation, we developed themes from FGDs and points jotted down in the self-memos. We found computer sciences and engineering students with better awareness than other students. The factors hindering e-waste disposal were lower monetary benefits for disposing of, breach of sensitive information, nostalgic association with devices, and non-availability of disposal facilities. Other variables like lower resale value and high family sharing increased the storage of e-devices and curbed e-waste disposal. The research is among a few initial attempts to explore e-waste awareness and factors hindering disposal behavior in e-waste receiving countries (e.g., Pakistan) and provides evidence from students who are the primary users. Our findings are crucial for policymakers and tech companies to take corrective actions, introduce monetary benefits, and secure disposal facilities to increase e-waste disposal.

\section{Research Highlights}

- We explored the students' e-waste awareness level and factors inducing the sale/storage of e-devices (management perspective).

- Student e-waste awareness level is low; only computer science students have awareness.

- Monetary benefits and family sharing can reduce the creation of e-waste.

\section{Introduction}

After the dot-com bubble burst in 2000, consumer technologies significantly changed human lives by becoming personal and portable. For instance, laptops and tablets replaced desktop computers, and cellphones replaced landline phones (Hillyer, 2020). More specifically, cellphones became an integral part of human life (Guo et al., 2015) after an exponential increase in their adoption, with 740 million subscriptions in 2000 to more than 8 billion in 2020. It implied that there are more cellphones globally than human beings (UN-ITU, 2019). Likewise, global laptop sales also surpassed desktop sales in 2009 (Arthur, 2009). Figure A1 in the appendix provides the global adoption trend of different technologies.

The exponential increase in technology consumption also generated considerable waste, regarded as waste electrical and electronic equipment (WEEE) or e-waste (Bhutta et al., 2011). A report by United Nations Environment Programme (2009) estimated the generation of 20-50 tons of e-waste annually. Years after, in 2020, a report on the Global E-waste Monitor 2020 reported the generation of 53.6 million 
tons (Mt) and 7.3 kilograms $(\mathrm{Kg})$ per capita e-waste globally. The figures may reach $74 \mathrm{Mt}$ by 2030; alternatively, a surge of $2 \mathrm{Mt}$ annually (Forti et al. 2020). Figure 1a provides the chronic increase in total and per capita e-waste production. Besides, Figure $1 \mathrm{~b}$ provides the distribution of e-waste in different regions, depicting that Asia tops the total e-waste generation bar and Europe ranks the highest in percapita production.

\section{Please Insert Figure 1a and 1b Here}

The decline in (consumption) life of consumer technologies, such as laptops, PCs, and cellphones, further extrapolate the e-waste generation (Lundgren, 2012). Walter (2020) reported that the average life of the laptop is 3-5 years, whereas Walton (n.d.) pointed out that the average life span of a cellphone is $\approx$ two years; after every two years, technology becomes obsolete. Therefore, the shorter lifespan and radical development of technologies have pushed consumers towards more innovative and latest products by substituting outdated or existing devices (Babbitt et al., 2009). Besides this, Kumar (2017) reported that the consumers avoid using second-hand machines to avoid low-quality products and unhygienic conditions (Kumar, 2017). Therefore, e-waste has become one of the most critical waste disposal issues of the present century due to consumers' awareness and behavior. It is causing human and environmental hazards due to its more toxic nature than conventional (municipal) wastes (Herat \& Agamuthu, 2012; Woodell, 2008a\&b). For instance, LEDs and LCDs in computers, laptops, and cellphones contain hazardous metals like cadmium, lead, and mercury, and the motherboards/circuits of the same devices contain beryllium, nickel, and zinc. Therefore, the disposal and recycling of these technologies (ewaste) have become imperative and critical (Bhutta et al., 2011).

The Global E-waste Monitor 2020 reckoned that the global documentation and recycling of e-waste are minimal (14.66\%); the highest is $42.5 \%$ in Europe, followed by $11.7 \%$ in Asia, $9.4 \%$ in the Americas, $8.8 \%$ in Oceania, and only $0.9 \%$ in Africa. Figure $1 \mathrm{~b}$ also provides the regional documented and recycled e-waste (Forti et al., 2020). However, the behavior of developed nations (top producers) is strange, which has divided the world into e-waste producers and receivers (Ahmad \& Rehman, 2010). Sajid et al. (2019) pointed out that developed economies dump outdated technologies to developing countries, usually through illegal means. A report on Regional E-waste Monitor also signified that China dumps a significant amount of e-waste ( $\approx 6.7 \mathrm{Mt}$ annually) in Asia (Honda et al. 2016).

In this case, Pakistan is at the receiving end (Ahmad \& Rehman, 2010) and imports the highest number of outdated e-devices/e-waste in the world (Borgen, 2021), mainly from the USA, Europe, Australia, Kuwait, Saudi Arabia, UAE, and Singapore (Iqbal et al., 2015). In 2020, Pakistan generated 433 Kilotons (Kt) of ewaste, where most of this waste was imported as scrap (WHO, 2021). Further, due to the widespread poverty, these devices are resold and reused even after their expiry, which posits the cause of potential hazards to human health and the environment (Abbas, 2010; lqbal et al., 2015). Therefore, due to high ewaste generation and consumption, Pakistan needs effective management (i.e., recycling and disposal) practices to deal with human and environmental threats. 
To this end, the literature concludes that consumer awareness is paramount for effective e-waste management. Baxter and Gram-Hanssen (2016) and Khetriwal et al. (2009) reported that consumer awareness and access to recycling are essential in determining the success of e-waste management. Likewise, Kwatra et al. (2013) indicated the importance of understanding consumers' knowledge and awareness as they produce e-waste. In Pakistan, Imran et al. (2017) pointed out that consumers, on average, lack awareness about e-waste disposal. Besides, the policies are insufficient to push e-waste recycling (Iqbal et al., 2015). Informal disposal systems are the central practice of disposing of e-waste without accounting to consider the environment, whereas consumers also do not know much about the disposal sites (Imran et al., 2017). Thus, as e-waste increases exponentially and the overall recycling rate below $15 \%$, it is imperative to study consumers' e-waste awareness and disposal practices (Ari, 2016). Besides, the government's initiatives to construct e-waste recycling facilities will never achieve their utmost efficiency without appropriate consumers' awareness (Sarath et al., 2015).

In the past, many studies investigated consumers' e-waste disposal behavior. Among those, Thi Thu Nguyen et al. (2019), Aboelmaged (2021), Arain et al. (2020), and Delcea et al. (2020) explored consumer e-waste disposal behavior to manage e-waste generation, while Gilal et al. (2019) explored the consumer e-waste disposal behavior with the help of Basic Psychological Need Theory and Word-of-Mouth. However, none of these studies focused on consumer awareness about e-waste and its disposal practices. Besides, a recent systematic literature review (SLR) by Gilal et al. (2021) highlighted the absence of comprehensive studies on consumers' awareness of e-waste and its disposal practices in developing nations, mainly in South Asia. Further, researchers conducted these scholarships on the mass level/ general public, which overlooked the specified responses from the actual consumers such as students, industry personnel, and managers. Hence, there is a dire need to explore students' e-waste awareness and its disposal practices to get customized, in-depth results, which would be beneficial to form the policies.

Therefore, we organized the present study to explore the students' awareness of e-waste and factors hindering e-waste disposal. Our first research question aimed to explore students' awareness about the ewaste disposal of laptops, PCs, and cellphones. The second question explored their awareness about the prominent factors hindering e-waste disposal (i.e., laptops, PCs, and cellphones). Research by Goyanes and Catalán-Matamoros (2017) illustrated that the laptops, PCs, and cellphones consumption is highest in students as nearly $99 \%$ of university students own and consume these technologies. The paper follows the qualitative research approach and undertakes the Focus Group Discussions (FGDs) to collect data from university students. Our study also adds to the literature in three ways. First, it provides students' ewaste awareness level. Next, it adds to the literature on the factors that induce the sale or storage of edevices. Researchers have rarely explored both these areas in Pakistan. This paper also provides the basis for the future exploration of consumer motivation and behavior towards e-waste disposal.

We have organized the following paper into six sections. The second section presents the available literature on e-waste awareness and disposal, followed by methodology, findings, and discussions in the 
following sections. The sixth section concludes the paper by providing theoretical and practical implications, propositions, and limitations.

\section{Literature Review}

Consumer awareness is critical to guide the behavioral outcomes as it directly impacts the intentions and attitudes to behave (Ishak \& Zabil, 2012). It is also paramount in inducing e-waste disposal (Makanyeza et al., 2021); however, only a few qualitative studies provide the evidence. For instance, Kumar et al. (2018) identified that low public awareness regarding electronic waste and the absence of effective policies are the two primary barriers that make e-waste disposal difficult. Besides, Roychowdhury et al. (2019) argued that the concern for information security plays a vital role in e-waste disposal.

From the consumer awareness perspective, Saphores et al. (2006) studied the willingness towards ewaste disposal in California, USA. The authors identified that the willingness to e-waste disposal depends on environmental awareness. Thi Thu Nguyen et al. (2019) identified that the awareness of the environment affected household behavior towards e-waste disposal. Kumar (2019) also indicated that consumers' concerns about the environment support their intentions to reutilize e-devices. Islam et al. (2020) emphasized increasing consumer environmental awareness. The results depicted the vital role of consumers' environmental awareness for e-waste in Pakistan. Likewise, Aboelmaged (2021), Arain et al. (2020), and Delcea et al. (2020) explored the consumer e-waste disposal behavior to manage e-waste generation. They concluded that consumer behavior is paramount for e-waste disposal, and environmental awareness leads to e-waste disposal.

From the theoretical perspective, Echegaray and Hansstein (2016) studied consumer e-waste intentions and disposal behavior with the help of the theory of planned behavior (TPB). Most of the respondents showed positive intention towards the e-waste disposal, indicating their awareness level. Following the TPB, Nduneseokwsssu et al. (2017), Thi Thu Nguyen. (2019), Wang et al. (2019), and Shaharudin et al. (2020) also utilized the TPB to determine the consumer e-waste disposal behavior. The authors concluded an encouraging connection between behavior and disposal intentions based on consumers' awareness level. Besides, Gilal et al. (2019) utilized the theoretical lens of Basic Psychological Need Theory to explore the word-of-mouth (WoM) on e-waste disposal. The results showed the positive role of positive WoM in increasing e-waste disposal.

Nevertheless, an extensive SLR by Gilal et al. (2021) suggested the dearth of comprehensive studies on ewaste awareness and disposal behavior in developing nations, mainly in South Asia. Besides, the researchers conducted all of these studies on the general public, which entirely overlooked the specified responses from the actual consumers such as students, industry personnel, and managers. Next, most of these studies cover developed countries, where e-waste disposal and recycling are high due to government policies. Only one study compared the e-waste awareness and disposal behavior of developing and developed countries (Borthakur \& Govind, 2017). They concluded a vast difference in awareness level and disposal behavior between developing and developed countries due to their 
socioeconomic and cultural differences. In a similar vein, Kwatra et al. (2013), Sarath et al. (2015), Imran et al. (2017) also emphasized the further exploration of consumer awareness regarding e-waste and its disposal practices.

Therefore, based on the literature, we conclude a lack of studies (collectively) exploring consumer awareness regarding e-waste and its disposal practices in developing countries. Our study attempts to fill this gap by undertaking personalized, in-depth probing responses.

\section{Methodology/methods}

\subsection{Philosophical Paradigm and Research Strategy}

This research study employed the constructivist paradigm to investigate consumer awareness regarding e-waste and disposal practices. As per Guba and Lincoln (1994), a researcher using the constructivist paradigm focuses on an agreement and recreates the meaning behind the behavior. It helps create the interconnection between participants and researchers and creates new knowledge from experience and reasoning (Guba and Lincoln, 1994). Researchers can also go back and forth with the data about what the researcher meant while asking the question and what participants meant while answering (Rudestam \& Newton, 1992). Next, the study used a case study approach to understand students' awareness regarding e-waste and its disposal practices. Creswell (2007) recognizes the case study as one of the five traditional qualitative strategies. The case study also considers the earlier improvement of theoretical propositions to coordinate the data collection and analysis process (Yin, 2003). Thus, the case study is instrumental in supporting and extending previously created theories.

\subsection{Sampling}

The sample is selected using the non-probability data collection approach with multi-stage sampling. Initially, we chose the sample based on purposive sampling, i.e., the students at all universities in Pakistan, as the students have more interaction with technologies in the universities. Research by Goyanes and Catalán-Matamoros (2017) illustrated that the laptops, PCs, and cellphones consumption is highest in students as nearly $99 \%$ of university students own and consume these technologies. Therefore, among different universities in Pakistan, we selected the participants from a university in Sukkur city based on convenience sampling. We found that the students at this university have received laptops and similar devices under various schemes, such as Prime Minister's Laptop Scheme, Book Review Competition, Math Olympiad, and THP Scholarship.

\subsection{Data Collection Method:}

We utilized the Focus Group Discussion (FGD) method to collect the data from university students. It allows the deliberate utilization of the connections to gather rich and in-depth data (Morgan 1996). We conducted four heterogeneous FGDs during 2021 with the students from four departments, i.e., Business Administration, Engineering, Computer Science, and Education. Each FGD randomly included a minimum 
of eight students from different educational levels, i.e., undergraduate, graduate, and postgraduate. Collectively, four FGDs comprised 34 students from different departments and degree programs.

\subsection{Data Collection Process:}

Initially, we briefed participants on the study purpose, foremost concerns, and their rights to withdraw from the FGD at any point in time. We also provided confidentiality assurance regarding their responses at the beginning and end of the FGDs. With their consent, each FGD was audio recorded for the sake of transcription (Merriam, 1998).

The first FGD included nine participants and lasted for 45 minutes, while the second FGD comprised nine participants and lasted for 33 minutes. Both were exploratory FGDs where participants could freely discuss and share their personal experiences about e-waste. Since similar themes emerged from both FGDs, we conducted two more confirmatory FGDs to verify the themes. The third FGD included eight participants and lasted for 28 minutes. No new theme emerged from the data; participants provided the same insights and experiences. Nevertheless, researchers also conducted a fourth FGD with eight participants to have more confidence in the data, which lasted for 27 minutes. Data became saturated until this point, and researchers were confident to move to develop second-and- third-order themes.

In each FGD, we used a semi-structured questionnaire, which included open-ended and probing questions to let participants freely move with ideas (Kvale, 1996). As we improved our questionnaire after each FGD, it became more structured during confirmatory FGDs. We also developed memos during the data collection to help during the data analysis in the latter part (Maxwell, 2005). Each memo incorporated the emerging themes, points of clarification, connection, and separation of the idea, participants' non-verbal gestures, attitudes, and direct statements that grabbed the researcher's attention (Bogdan \& Biklin, 1982). Precisely, memos made it conceivable to record what we saw and why we saw.

Once the data was collected, the researchers carefully transcribed the audio recordings in a text format. Each researcher transcribed one interview recording. The researchers also reviewed each other's transcribed files to avoid the researcher's personal bias and enhance the reliability since the "accurate transcripts are necessary for valid analysis and interpretation of interview data" (Mishler, 1986).

\section{Data Analysis And Results}

\subsection{Validity and Reliability: Role of the Researcher}

The researcher plays the role of the instrument in any qualitative research study. Therefore, research's personal biases from past experiences can affect the validity and reliability of the data (Maxwell, 2005) and results (Strauss \& Corbin, 1998). We carefully dealt with the issue and maintained it in three ways, as Lincoln \& Guba (1985) also suggested. Initially, during the data collection, one of the researchers played the devil's advocate role in each FGD to take the conversation back to the primary concern. Next, the researchers also cross-checked each others' transcribed documents and codes to reduce the effects of 
personal biases. Finally, the researchers incorporated adequate and pertinent statements from the participants to validate the study outcomes, as Maxwell (2005) suggested.

\subsection{Demographics}

The results depicted that in four FGDs, there were 29 males and 5 females, from four departments, i.e., Business Administration ( $n=19)$, Electric and Electronic Engineering $(n=8)$, Computer Sciences $(n=6)$, and Education $(n=1)$. More students were from undergraduate degrees $(n=26)$, then graduate $(n=6)$, and postgraduate $(n=2)$. Lastly, students from Electrical and Electronic Engineering $(n=35)$ and Computer Sciences $(n=30)$ departments had more e-devices than any other department. Below given Tables $1 \mathrm{a}$ and $1 \mathrm{~b}$ provide the detailed results.

\section{Please Insert Table 1a and 1b Here}

\subsection{Findings}

Based on the coding methods by Miles et al. (2018), we generated first-order codes followed by secondorder and third-order codes. Below we divided our results into two primary dimensions, i.e., students' awareness regarding e-waste and its disposal practices. We also developed a conceptual framework that depicts the awareness and factors hindering e-waste disposal. Below, Figure 2 illustrates the developed connections.

\section{Please Insert Figure 2 Here}

\subsubsection{E-waste Awareness}

Under the students' e-waste awareness, the study explored three dimensions, i.e., e-waste awareness, the awareness of environmental consequences of e-waste, and the awareness of e-waste management practices. Table A1 in the appendix provides the detailed results.

Concerning the e-waste awareness, $50 \%$ of participants $(n=17)$ from four FGDs already knew the concept of e-waste due to their degree programs. Specifically, the students from the Computer Sciences and Engineering degrees already knew the concept of e-waste. The results implied that one in every two students understands e-waste. The next theme was the students' self-interest in contemporary topics, such as global warming and waste. A few participants came to know about e-waste from World Bank documentaries, and the rest of the participants were not familiar with the concept of e-waste. Their responses concluded that e-waste comprises Electrical and Electronic Equipment (EEE), which has become dysfunctional or outdated due to generational advancements.

Regarding the second dimension of e-waste (the awareness of environmental consequences of e-waste), the frequently emerging theme was greenhouse gasses (GHG) and radiations, which hurt the locality, humans, and animals. All participants provided the similar consequences our environment can face from e-waste. Following this, we asked them their preferences to buy an electronic product produced without 
harming the environment. They all pointed out that they will initially evaluate its usefulness based on the price and consider the feasibility of this product. Hence, the lower cost and feasibility would motivate students to buy an environmentally friendly e-device.

Lastly, concerning the third dimension of e-waste awareness (awareness of e-waste management practices), the frequently emerging themes are as follows: (i) reuse, (ii) family sharing, and (iii) repair of dysfunctional devices. The participants elaborated that they reuse their products to avoid e-waste generation; however, the reuse of these devices is less due to rapid technological advancement. Next, the participants illustrated that they frequently shared their out-of-use devices with their family members, pointing out that the family sharing is high to manage e-waste. To probe further, we asked them about the benefits of family sharing. These included (i) fewer security issues, (ii) better than storing, (iii) providing a sense of nostalgia attachment, and (iv) serving as gifts for youngers. Lastly, the respondents also mentioned the possible option of repairing dysfunctional devices to reduce e-waste.

\subsubsection{Awareness of Factors Hindering the E-waste Disposal}

To achieve our second research question, we asked participants about the possible factors hindering ewaste disposal. To probe further, we divided our questions into three dimensions. These include factors hindering e-waste disposal, factors inducing the sale or storage of e-devices, and the solutions to reduce e-waste. Table A1 in the appendix also provides the detailed results.

Concerning the factors hindering e-waste disposal, three themes emerged from the FGDs. These include (i) high-security concerns, (ii) monetary benefits, (iii) nostalgic association with the product, (iv) lack of awareness programs, and ( $v$ ) complicated disposal process. The participants mentioned significant concern about the data breach while disposing of their devices and required monetary benefits to dispose of their products. They also showed their association with e-devices. For instance, most of them were not motivated to sell or dispose of the first cellphone or phone they bought from their salary.

The participants also mentioned the lack of awareness programs regarding the disposal of e-devices. Students argued that they do not think their stored devices could come under e-waste. They showed more significant concern about the work of the governmental organization in managing e-waste, arguing that it is the work of the concerned organizations to provide proper awareness to its people. Lastly, the participants pointed out that e-waste disposal is a complicated process that takes time. Besides, they do not find time to go to the disposal sites or market and sell out-of-use non-functional devices, and it is easier to store their devices in their homes; therefore, there is no need to dispose of them. We triangulated these factors by asking participants their stated willingness. We asked whether they are willing to dispose of their products under the condition that a system completely disposes of their e-devices, i.e., no system error ( $100 \%$ disposal of data). Surprisingly, most participants refused to dispose of their e-devices and showed privacy concern over disposing of their products through the (hypothetical) system. However, their responses changed when we provided them with monetary benefits. 
Regarding the second dimension (factors inducing the sale or storage of e-devices), the frequently emerging theme inducing the sale of e-devices were: (i) high monetary benefits and (ii) family sharing. Half participants mentioned that they sold their e-devices in the market due to good monetary benefits. The remaining mentioned that they sold to family members to feel a sense of attachment. We also explored the factors increasing the storage of e-waste devices; alternatively, the factors hindering the sales of e-devices. The participants' responses converged in four themes, i.e., (i) leakage of sensitive information, (ii) nostalgic association, (iii) lower resale price, and (iv) lack of information about disposal sites. All were anxious about the meager price and information breach, including pictures, passwords, and related data. They also stated their nostalgic association with the devices. Lastly, the participants pointed out that they do not know about any disposal facility in their respective cities.

Lastly, concerning the third dimension (solutions to reduce e-waste), the participants' responses converged in three themes, i.e., solutions at (i) individual-level, (ii) organizational-level, and (iii) governmental-level. They mentioned that we could reduce e-waste individually by (i) reusing out-of-use edevices and (ii) high family sharing. At the organizational level, the three dimensions were: (i) developing proper channels by tech-based organizations and (ii) extracting precious metals. Nevertheless, all elaborated that the governments' role is paramount in managing and reducing e-waste; there is a need for the government to show some severe concern and take valuable actions to manage the emerging issue of e-waste.

Summing all, participants' answers revolved around three themes, i.e., (i) high or marginal monetary benefits, (ii) awareness campaigns organized by the concerned governmental institutes, (iii) strict penalty for not properly disposing of the e-devices.

\section{Discussion}

We focused on exploring students' awareness of e-waste and the prominent factors hindering its disposal. We organized four FGDs of university students in Pakistan and divided our findings into two primary dimensions, i.e., e-waste awareness and factors hindering disposal. Each dimension focused on three sub-dimensions, i.e., the awareness of e-waste, the awareness of environmental consequences of ewaste, and awareness of e-waste management practices under the e-waste awareness, and factors hindering e-waste disposal, factors inducing the sale or storage of e-devices, and the solutions to reduce e-waste under factors hindering the e-waste disposal. Below we discuss each dimension.

\subsection{E-waste Awareness}

\subsubsection{Awareness of E-waste}

The results concluded that students consider e-waste as laptops, PCs, and cellphones that are not functional and have become outdated. This definition is similar to the definition proposed by Robinson (2009). Besides, half participants learned about e-waste from their degree programs (Computer Sciences and Engineering) and various other sources such as documentaries on recycling by World Bank and 
Indian agencies. The remaining learned it during FGDs. Thus, we concluded that consumer interest and environment induce an awareness of contemporary technologies and issues, such as e-waste.

\subsubsection{Awareness of Environmental Consequences of E-waste}

Since the literature provided the association of environmental consequences awareness with e-waste awareness (Echegaray \& Hansstein, 2017), we checked the awareness of the environmental consequences. The results depicted that the participants across all FGDs knew the environmental effects of e-waste. These could be in the shape of increased greenhouse gases $(\mathrm{GHG})$ and radiation, causing various health issues to the locality, animals, and humans. Other quantitative studies by Lundgren (2012), Chan and Wong (2013), Song and Li (2015), Awasthi et al. (2016), and Kumar (2019) also reported similar environmental consequences. Next, the participants did not show any willingness to buy green edevices when we explored their willingness to pay for a product manufactured without harming nature. All of them showed apprehension over the need and the cost of the product, alternatively mentioning that regardless of whether those products are produced under green conditions, they will only buy those if these devices are valuable and cost-effective. Thus, we inferred that the consumers see the product's usefulness according to their needs and the cost. Quantitative studies like Kumar et al. (2019) and Islam et al. (2020) reported similar results.

\subsubsection{Awareness of E-waste Management Practices}

In addition to the above dimensions, we explored consumer awareness regarding e-waste management practices. We focused on whether our participants had ever thought about the management of e-waste or not. Therefore, we presented e-waste in the shape of dysfunctional devices. The results depicted that half of the participants had unusable devices at their homes, and half of them had undertaken various options to manage them. For instance, they used Hard Disk Drive on another laptop or as an external data bank. However, the reuse of e-devices is less due to rapid technological advancement. For instance, the participants mentioned that the HDDs have become outdated due to Solid-State Drives (SSDs). Besides, DDR3 RAMs are not compatible with the laptops using DDR4 RAMs. They also disagreed with the notion of repairing dysfunctional devices due to the high cost compared to buying a new product.

\subsection{Awareness of Factors Hindering the E-waste Disposal}

\subsubsection{Factors Hindering E-waste Disposal}

The factors hindering the e-waste disposal included the high-security concerns regarding the data breach, monetary benefits, nostalgic association with the product, lack of awareness programs, and complicated disposal process. Related to the data breach and monetary benefits, the participants asked for the security of their data and some monetary benefit to dispose of their product. Other quantitative studies like Mishima \& Nishimura (2016) reported similar results. To probe further, we asked them if a disposal system provides them the $100 \%$ surety for disposing of their products, would they go for disposing of their product. Surprisingly, none supported the notion; however, all agreed to dispose of it when we 
provided them with some monetary benefits. Thus, we inferred that the consumers are more anxious about the monetary benefits and compare it with the price they can get in the market.

Next, their responses highly contradicted between "sharing with the family members" and "monetary benefits." Thus, we asked them whether they would still sell their devices in the market for monetary benefits or share them with their family members due to safety concerns. Participants explicitly mentioned their preference for security and benefitting their own family. Therefore, we inferred that security comes first for consumers if they decide between monetary benefits and security. Another thing that appeared was the nostalgic association of participants with their e-devices. They feel some association with the devices they have bought and will show them to their descendants. They also suggested the lack of awareness programs about e-waste disposal as e-waste disposal is a complicated process. Lastly, our participants had also shared these devices with their siblings as gifts.

\subsubsection{Factors Inducing the Sale or Storage of E-devices}

As we were concerned about exploring the possible factors behind the sale or storage of e-devices as an alternative to the e-waste disposal, we explored participants' preferences for selling or storing the edevices. Students showed severe concern for monetary benefits and sold their devices to receive a high price. However, their responses changed while sharing/selling their devices with their family members. Our participants pointed out that they feel attachment when sharing with their family. We also concluded that the consumers are concerned about their data leakage, so they do not dispose of the e-devices they use. Quantitative studies like Nnorom et al. (2009), Wang et al. (2011), and Mishima and Nishimura (2016) reported similar results. Since both of these themes were parallel to previously emerged themes, we inferred that the participants are more concerned about their data and possess some nostalgic association with their products.

\subsubsection{Solutions to Reduce E-Waste}

The solutions to reducing e-waste converged into three levels, i.e., individual, organizational, and governmental levels. All of the participants showed great concern for the measures taken by the local and federal governments. They must organize awareness campaigns, provide high or marginal benefits for ewaste disposal, and penalize non-e-waste disposal. Quantitative studies like Cai et al. (2020) and Delcea et al. (2020) also emphasized the governmental role in increasing e-waste disposal. The results also concluded that the organizations producing e-devices must develop a sustainable channel for the disposal and extraction of precision metals. Lastly, at the individual level, there is a need to show significant concern over the misuse of resources, particularly metals.

\section{Conclusion, Implications, And Future Research Agenda}

This study explored the student awareness about e-waste (laptops/PCs and mobile phones) disposal and the prominent factors that hinder its disposal. It also tried to fill the gap and highlighted possible research areas in consumer e-waste awareness. We used the case-study research approach and a semi-structured 
questionnaire to collect the student data to achieve the study purpose. The key findings concluded that students consider e-waste as out-of-use and non-functional EEE, including laptops, PCs, and mobile phones, that are not functional and have become outdated. Only half of the students (50\%) knew about the concept of e-waste, particularly those who have some connection with the computer sciences or engineering degrees. The major factors that hinder the e-waste disposal are: (i) high monetary benefit required, (ii) sensitive information breach, (iii) family sharing, (iv) nostalgic association, and (v) no disposal facility. In last, we provide propositions and both theoretical and practical implications.

\subsection{Theoretical and Practical Implications}

We contributed to the existing theory of self-interest (Wolf 1986). The findings illustrated that students are aware of the matters that seem interesting to them. Likewise, our results further strengthened the theory of waste management (Pongrácz et al., 2004). It implies that e-waste awareness plays a vital role in ewaste disposal. In contrast, e-waste management can be effective when consumers know the process and consequences. We extend our findings to the information security concept, which discusses data security as the barrier to e-waste disposal. Henceforth, we have found that information security and monetary benefits restrict e-waste disposal (Roychowdhury et al., 2019). Next, we also add to the existing literature on consumer environmental awareness as it plays a vital role in understanding e-waste. These findings are crucial for the governmental and local organizations responsible for e-waste disposal. Thus, we propose that responsible institutions develop firm policies to tackle the increasing issue of e-waste in Asia.

\subsection{Future Research Agenda}

While explaining the possible factors hindering e-waste disposal, our participants were inconclusive between the monetary benefits and security concerns. To probe further, we repeatedly asked questions, which produced different answers. For instance, we asked participants their willingness to dispose of their products if a system completely disposes of their devices. Surprisingly, most refused to dispose of their e-devices and showed privacy concerns. Nevertheless, their responses changed when we provided them with monetary benefits. The literature also produces mixed results. Heacock et al. (2016), Marke et al. (2020), and Chen et al. (2021) indicated security concern as a significant factor behind e-waste disposal, whereas Vats and Singh (2014), Lakshmi and Raj (2017), and Yang et al. (2021) mentioned no monetary benefits behind limited e-waste disposal. Therefore, we concluded that security concerns and monetary benefits need more in-depth exploration and investigation. Based on our findings, we propose:

P1: Going with the future: Exploring the significance of security concerns versus monetary benefits in inducing e-waste disposal may provide essential insights to e-waste disposal institutions.

While doing the literature review, we also discovered that the researchers widely use the theory of planned behavior (and the theory of reasoned action) to explore consumers' e-waste intentions and behavior towards disposal. For instance, Echegaray and Hansstein (2016) studied consumer e-waste intentions and disposal behavior using a theory of planned behavior (TPB). Other studies also employed an 
information security concept, a theory of self-interest (Wolf 1986), and a theory of waste management (Pongrácz et al., 2004). These theories are also valuable in understanding consumer e-waste behavior. Therefore, we concluded that the theories explaining and exploring the consumer e-waste disposal behavior are concentrated. Based on our exploration, we posit:

P2: $\quad$ Theoretical Lens: Taking other motivational theories such as self-determination and organismic integration theories would help understand consumer e-waste disposal behavior from intrinsic and extrinsic motivational aspects.

\subsection{Study Limitations}

The researchers also faced limitations. First, we conducted the FGDs during the COVID-19 pandemic, making it harder to access students in the university and record their responses. Due to this, we could not conduct in-depth interviews after FGDs to triangulate the data and findings. Second, we collected the data from the university in one city of Pakistan with the intent that the students at the said university frequently interact with e-devices than any other university in Pakistan. However, the students' awareness and behavior may change who do not use the technologies frequently. Third, our participants only included the students from business administration $(n=19)$, electrical and electronic engineering $(n=8)$, and computer sciences $(n=6)$ departments. The COVID-19 restrictions made us overlook other departments, such as social and natural sciences, agricultural sciences, economics, education, literature, and physical education. Therefore, we propose that future researchers collect data from these departments of the universities. Besides this, the researchers may address awareness and e-waste disposal at the organizational level as they also cause the massive generation of e-waste. Lastly, future studies may also check the conceptual framework of the present study. Researchers may take one-to-one interviews with diverse groups and provide more insights and confidence from the ground data.

\section{Declarations}

\section{DATA AVAILABILITY STATEMENT}

Research data will be available upon request from authors.

\section{FUNDING STATEMENT}

Not applicable.

\section{CONFLICT OF INTEREST DISCLOSURE}

The authors declare no conflicts of interest.

\section{ETHICS APPROVAL STATEMENT}

All ethics were followed during the data collection and manuscript writing. 


\section{PERMISSION TO REPRODUCE MATERIAL FROM OTHER SOURCES}

This research article does not include any document for which permission to reproduce material was required.

\section{ACKNOWLEDGEMENTS}

We are thankful to all students and management of Sukkur IBA University for their support throughout the research work. Further, we are highly grateful to the students for providing their valuable responses regarding e-waste awareness and disposal. We also want to thank our peers for the continuous feedback during the discussion.

\section{References}

Abbas, Z. (2010, July). E-waste management in Pakistan. In Regional Workshop on E-waste/WEEE Management, Osaka, Japan (pp. 6-9).

Aboelmaged, M. (2021). E-waste recycling behaviour: An integration of recycling habits into the theory of planned behaviour. Journal of Cleaner Production, 278, 124182.

Ahmad, S., \& Rehman, M. (2010). ICTs and environmental sustainability: Islamic Republic of Pakistan. In Global Information Society Watch 2010: Focus on ICTs and environmental sustainability. Association for Progressive Communications (APC) and Hivos. https://giswatch.org/sites/default/files/pak-listo.pdf.

Arain, A. L., Pummill, R., Adu-Brimpong, J., Becker, S., Green, M., Ilardi, M., ... \& Neitzel, R. L. (2020). Analysis of e-waste recycling behavior based on survey at a Midwestern US University. Waste Management, 105, 119-127.

Ari, V. (2016). A review of technology of metal recovery from electronic waste. E-Waste in transition-From pollution to resource. InTech, 121-158.

Awasthi, A. K., Zeng, X., \& Li, J. (2016). Relationship between e-waste recycling and human health risk in India: a critical review. Environmental Science and Pollution Research, 23(12), 11509-11532.

Babbitt, C. W., Kahhat, R., Williams, E., \& Babbitt, G. A. (2009). Evolution of product lifespan and implications for environmental assessment and management: a case study of personal computers in higher education. Environmental science \& technology, 43(13), 5106-5112.

Bai, H., Wang, J., \& Zeng, A. Z. (2018). Exploring Chinese consumers' attitude and behavior toward smartphone recycling. Journal of cleaner production, 188, 227-236.

Baxter, J., \& Gram-Hanssen, I. (2016). Environmental message framing: enhancing consumer recycling of mobile phones. Resources, Conservation and Recycling, 109, 96101. https://doi.org/10.1016/j.resconrec.2016.02.012. 
Bogdan, R. C., \& Biklen, S. K. (1982). Qualitative research for education: An introduction to theory and methods. Boston: Allyn and Bacon, Inc.

Borthakur, A., \& Govind, M. (2017). Emerging trends in consumers' E-waste disposal behaviour and awareness: A worldwide overview with special focus on India. Resources, Conservation and Recycling, 117, 102-113.

Cai, K., Song, Q., Peng, S., Yuan, W., Liang, Y., \& Li, J. (2020). Uncovering residents' behaviors, attitudes, and WTP for recycling e-waste: a case study of Zhuhai city, China. Environmental Science and Pollution Research, 27(2), 2386-2399.

Cairns, C. N. (2005, May). E-waste and the consumer: improving options to reduce, reuse and recycle. In Proceedings of the 2005 IEEE International Symposium on Electronics and the Environment, 2005. (pp. 237-242). IEEE.

Chan, J. K. Y., \& Wong, M. H. (2013). A review of environmental fate, body burdens, and human health risk assessment of PCDD/Fs at two typical electronic waste recycling sites in China. Science of the total environment, 463, 1111-1123.

Chen, H., Turel, O., \& Yuan, Y. (2021). E-waste information security protection motivation: the role of optimism bias. Information Technology \& People.

China Environmental Protection Online (CEPO) (2015). E-waste production set a record, one of the "contributors" of China National Chengchi University. News. Published on April 21, 2015. https://www.hbzhan.com/news/Detail/96635.html.

Creswell, J. (2007). Qualitative inquiry \& research design: Choosing among five approaches (2nd ed.). Thousand Oaks, CA: Sage

Debnath, B., Das, A., \& Das, A. (2022). Towards circular economy in e-waste management in India: Issues, challenges, and solutions. In Circular Economy and Sustainability (pp. 523-543). Elsevier.

Delcea, C., Crăciun, L., loanăș, C., Ferruzzi, G., \& Cotfas, L. A. (2020). Determinants of Individuals' E-Waste Recycling Decision: A Case Study from Romania. Sustainability, 12(7), 2753.

de Oliveira Neto, J. F., Silva, M. M., \& Machado Santos, S. (2019). A Mini-Review of E-Waste Management in Brazil: Perspectives and Challenges. CLEAN-Soil, Air, Water, 47(9), 1900152.

de Oliveira, C. R., Bernardes, A. M., \& Gerbase, A. E. (2012). Collection and recycling of electronic scrap: A worldwide overview and comparison with the Brazilian situation. Waste management, 32(8), 1592-1610.

Dhir, A., Koshta, N., Goyal, R. K., Sakashita, M., \& Almotairi, M. (2021). Behavioral reasoning theory (BRT) perspectives on E-waste recycling and management. Journal of Cleaner Production, 280, 124269. 
Dhir, A., Malodia, S., Awan, U., Sakashita, M., \& Kaur, P. (2021). Extended valence theory perspective on consumers'e-waste recycling intentions in Japan. Journal of Cleaner Production, 312, 127443.

Echegaray, F., \& Hansstein, F. V. (2017). Assessing the intention-behavior gap in electronic waste recycling: the case of Brazil. Journal of Cleaner Production, 142, 180-190.

Fayaz, S. M., Abdoli, M. A., Baghdadi, M., \& Karbasi, A. (2021). Ag removal from e-waste using supercritical fluid: improving efficiency and selectivity. International Journal of Environmental Studies, 78(3), 459-473.

Gilal, F. G., Shah, S. M. M., Adeel, S., Gilal, R. G., Gilal, N. G., (2021). Consumer disposal behavior: A systematic review and research agenda. International Journal of Consumer Studies. Published online on December 02, 2021. DOI: https://doi.org/10.1111/ijcs.12767

Gilal, F. G., Zhang, J., Gilal, N. G., \& Gilal, R. G. (2019). Linking self-determined needs and word of mouth to consumer e-waste disposal behaviour: A test of basic psychological needs theory. Journal of Consumer Behaviour, 18(1), 12-24. https://onlinelibrary.wiley.com/doi/full/10.1002/cb.1744.

Goyanes, M., \& Catalán-Matamoros, D. (2017). Ubiquitous laptop use in higher education: Multitasking and students' perception of distraction in a European setting. First Monday.

Guba, E.G., \& Lincoln, Y. S. (1994). Competing paradigms in qualitative research. In N. K. Denzin \& Y. S. Lincoln (Eds.), Handbook of qualitative research (pp. 105- 117). Thousand Oaks, CA: Sage.

Guo, X., Liu, J., Qin, H., Liu, Y., Tian, Q., \& Li, D. (2015). Recovery of metal values from waste printed circuit boards using an alkali fusion-leaching-separation process. Hydrometallurgy, 156, 199-205.

Guo, X., Yan, K., 2017, Estimation of obsolete cellular phones generation: A case study of China. Science of the Total Environment 575, 321-329.

Heacock, M., Kelly, C. B., \& Suk, W. A. (2016). E-waste: the growing global problem and next steps. Reviews on environmental health, 31(1), 131.

Herat, S., \& Agamuthu, P. (2012). E-waste: a problem or an opportunity? Review of issues, challenges, and solutions in Asian countries. Waste Management \& Research, 30(11), 1113-1129.

Ilankoon, I. M. S. K., Ghorbani, Y., Chong, M. N., Herath, G., Moyo, T., \& Petersen, J. (2018). E-waste in the international context-A review of trade flows, regulations, hazards, waste management strategies and technologies for value recovery. Waste Management, 82, 258-275.

Iqbal, M., Breivik, K., Syed, J. H., Malik, R. N., Li, J., Zhang, G., \& Jones, K. C. (2015). Emerging issue of ewaste in Pakistan: a review of status, research needs and data gaps. Environmental Pollution, 207, 308318. 
Ishak, S., \& M. Zabil, N. F. (2012). Impact of Consumer Awareness and Knowledge to Consumer Effective Behavior. Asian Social Science, 8(13). doi:10.5539/ass.v8n13p108

Islam, M. T., Dias, P., \& Huda, N. (2020). Waste mobile phones: A survey and analysis of the awareness, consumption, and disposal behavior of consumers in Australia. Journal of Environmental Management, 275, 111111.

Imran, M., Haydar, S., Kim, J., Awan, M. R., \& Bhatti, A. A. (2017). E-waste flows, resource recovery and improvement of legal framework in Pakistan. Resources, Conservation and Recycling, 125, 131-138.

Islam, M. T., Dias, P., \& Huda, N. (2021). Young consumers' e-waste awareness, consumption, disposal, and recycling behavior: A case study of university students in Sydney, Australia. Journal of Cleaner Production, 282, 124490.

Kahhat, R., Kim, J., Xu, M., Allenby, B., Williams, E., \& Zhang, P. (2008). Exploring e-waste management systems in the United States. Resources, conservation, and recycling, 52(7), 955-964.

Khetriwal, D. S., Kraeuchi, P., \& Widmer, R. (2009). Producer responsibility for e-waste management: key issues for consideration-learning from the Swiss experience. Journal of environmental management, 90(1), 153-165. https://doi.org/10.1016/j.jenvman.2007.08.019

Kruger, H. A., \& Kearney, W. D. (2006). A prototype for assessing information security awareness. Computers \& security, 25(4), 289-296.

Kumar, A., 2017. Extended TPB model to understand consumer selling" behaviour Implications for reverse supply chain design of mobile phones. Asia Pacific Journal of Marketing and Logistics. 29 (4), 1-26.

Kumar, A. (2019). Exploring young adults' e-waste recycling behaviour using an extended theory of planned behaviour model: A cross-cultural study. Resources, Conservation and Recycling, 141, 378-389.

Kumar, A., \& Dixit, G. (2018). An analysis of barriers affecting the implementation of e-waste management practices in India: A novel ISM-DEMATEL approach. Sustainable Production and Consumption, 14, 36-52.

Kvale, W. (1996). Interviews: An introduction to qualitative research interviewing. Thousand Oaks, CA: Sage Publications, Inc.

Kwatra, S., Pandey, S. and Sharma, S. (2014), "Understanding public knowledge and awareness on ewaste in an urban setting in India: A case study for Delhi", Management of Environmental Quality, 25(6), 752-765. https://doi.org/10.1108/MEQ-12-2013-0139.

Lakshmi, S., \& Raj, A. (2017). A Review Study of E-Waste Management in India. Asian Journal of Applied Science and Technology (AJAST) Volume, 1, 33-36. 
Li, J., Tian, B., Liu, T., Liu, H., Wen, X., \& Honda, S. I. (2006). Status quo of e-waste management in mainland China. Journal of Material Cycles and Waste Management, 8(1), 13-20.

Lincoln, Y. S., \& Guba, E. G. (1985). Naturalistic inquiry. Newbury Park, CA: Sage Publications, Inc.

Lu, C., Zhang, L., Zhong, Y., Ren, W., Tobias, M., Mu, Z., ... \& Xue, B. (2015). An overview of e-waste management in China. Journal of Material Cycles and Waste Management, 17(1), 1-12.

Lukhanyu, M. (2020). Where to Buy a Gaming Laptop? Tech

Moran. https://techmoran.com/2020/09/16/where-to-buy-a-gaming-laptop/amp/

Lundgren K., 2012. The Global Impact of e-Waste: Addressing the Challenge. International Labour Office, Programme on Safety and Health at Work and the Environment (SafeWork), Sectoral Activities Department (SECTOR). Geneva International Labour Office.

Marke, A., Chan, C., Taskin, G., \& Hacking, T. (2020). Reducing e-waste in China's mobile electronics industry: the application of the innovative circular business models. Asian Education and Development Studies.

Makanyeza, C., Svotwa, T. D., \& Jaiyeoba, O. (2021). The effect of consumer rights awareness on attitude and purchase intention in the hotel industry: Moderating role of demographic characteristics. Cogent Business \& Management, 8(1), 1898301.

Maxwell, J. A. (2005). Qualitative research design (2nd ed.). Thousand Oaks, CA: Sage Publications, Inc.

McGrath, R. G., (2019). The Pace of Technology Adoption is Speeding-up. Harvard Business

Review. https://hbr.org/2013/11/the-pace-of-technology-adoption-is-speeding-up

Merriam, S. B. (1998). Qualitative research and case study applications in education. San Francisco: Jossey-Bass Publishers.

Miles, M. B., Huberman, A. M., \& Saldaña, J. (2018). Qualitative data analysis: A methods sourcebook. Sage publications.

Mishima, K., \& Nishimura, H. (2016). Requirement analysis to promote small-sized E-waste collection from consumers. Waste Management \& Research, 34(2), 122-128.

Mishler, E. G. (1986). Research interviewing: Context and narrative. Cambridge, MA: Harvard University Press.

Morgan D. (1996) Focus groups. Annual Review Sociology 22, 129-152. Annual review inc.

Mundada, M. N., Kumar, S., \& Shekdar, A. V. (2004). E-waste: a new challenge for waste management in India. International Journal of Environmental Studies, 61(3), 265-279. 
Nduneseokwu, C. K., Qu, Y., \& Appolloni, A. (2017). Factors influencing consumers' intentions to participate in a formal e-waste collection system: A case study of Onitsha, Nigeria. Sustainability, 9(6), 881.

Nnorom, I. C., Ohakwe, J., \& Osibanjo, O. (2009). Survey of willingness of residents to participate in electronic waste recycling in Nigeria-A case study of mobile phone recycling. Journal of cleaner production, 17(18), 1629-1637.

Parajuly, K., Thapa, K. B., Cimpan, C., \& Wenzel, H. (2018). Electronic waste and informal recycling in Kathmandu, Nepal: challenges and opportunities. Journal of Material Cycles and Waste Management, 20(1), 656-666.

Pariatamby, A., \& Victor, D. (2013). Policy trends of e-waste management in Asia. Journal of Material Cycles and Waste Management, 15(4), 411-419.

Pongrácz, E., Phillips, P. S., \& Keiski, R. L. (2004, June). Evolving the theory of waste managementimplications to waste minimization. In Proceedings of the Waste minimization and Resources Use Optimization Conference (pp. 61-7).

Ramzan, S., Liu, C., Munir, H., \& Xu, Y. (2019). Assessing young consumers' awareness and participation in sustainable e-waste management practices: a survey study in Northwest China. Environmental Science and Pollution Research, 26(19), 20003-20013.

Robinson, B. H. (2009). E-waste: an assessment of global production and environmental impacts. Science of the total environment, 408(2), 183-191.

Roychowdhury, P., Alghazo, J. M., Debnath, B., Chatterjee, S., \& Ouda, O. K. M. (2019). Security threat analysis and prevention techniques in electronic waste. In Waste Management and Resource Efficiency (pp. 853-866). Springer, Singapore.

Rudestam, K. E., \& Newton, R. R. (1992). Surviving your dissertation: A comprehensive guide to content and process. Newbury Park, CA: Sage Publications, Inc.

Sarofim, S., Minton, E., Hunting, A., Bartholomew, D. E., Zehra, S., Montford, W., ... \& Paul, P. (2020). Religion's influence on the financial well-being of consumers: A conceptual framework and research agenda. Journal of Consumer Affairs, 54(3), 1028-1061.

Sajid, M., Syed, J. H., Iqbal, M., Abbas, Z., Hussain, I., \& Baig, M. A. (2019). Assessing the generation, recycling, and disposal practices of electronic/electrical-waste (E-Waste) from major cities in Pakistan. Waste management, 84, 394-401.

Saphores, J. D. M., Nixon, H., Ogunseitan, O. A., \& Shapiro, A. A. (2006). Household willingness to recycle electronic waste: an application to California. Environment and Behavior, 38(2), 183-208. 
Sarath, P., Bonda, S., Mohanty, S., \& Nayak, S. K. (2015). Mobile phone waste management and recycling: Views and trends. Waste management, 46, 536-545. https://doi.org/10.1016/j.wasman.2015.09.013

Shaharudin, M. R., Said, R., Hotrawaisaya, C., Nik Abdul Rashid, N. R., \& Azman Perwira, N. F. S. (2020). Linking determinants of the youth's intentions to dispose of portable e-waste with the proper disposal behavior in Malaysia. The Social Science Journal, 1-15.

Song, Q., \& Li, J. (2015). A review on human health consequences of metals exposure to e-waste in China. Environmental Pollution, 196, 450-461.

Spacey, J. (2017). 20 Examples of Consumer Technology.

Simplicable. https://simplicable.com/new/consumer-technology\#: :text=Consumer\% 20technology\%20is\%20any\%20technology,and\%20businesses\%20to\%20achieve\%20objectives.

Sthiannopkao, S., \& Wong, M. H. (2013). Handling e-waste in developed and developing countries: Initiatives, practices, and consequences. Science of the Total Environment, 463, 1147-1153.

Strauss, A. M., \& Corbin, J. (1998). Basics of Qualitative Research: Techniques and Procedures for Developing Grounded Theory. (3rd Edition.). Newbury Park, CA: Sage Publications, Inc.

Streicher-Porte, M., Widmer, R., Jain, A., Bader, H. P., Scheidegger, R., \& Kytzia, S. (2005). Key drivers of the e-waste recycling system: Assessing and modelling e-waste processing in the informal sector in Delhi. Environmental impact assessment review, 25(5), 472-491.

Tan, Q., Duan, H., Liu, L., Yang, J., \& Li, J. (2018). Rethinking residential consumers' behavior in discarding obsolete mobile phones in China. Journal of cleaner production, 195, 1228-1236.

Thakur, P., \& Kumar, S. (2021). Evaluation of e-waste status, management strategies, and legislations. International Journal of Environmental Science and Technology, 1-10.

Thi Thu Nguyen, H., Hung, R. J., Lee, C. H., \& Thi Thu Nguyen, H. (2019). Determinants of residents' Ewaste recycling behavioral intention: A case study from Vietnam. Sustainability, 11(1), 164.

Thomson, M. E. \& von Solms, R. (1998), "Information security awareness: educating your users effectively", Information Management \& Computer Security, 6(4), 167-

173. https://doi.org/10.1108/09685229810227649

Tiep, H. S., Kin, T. D. Y., Ahmed, E. M., \& Teck, L. C. (2015). E-waste management practices of households in Melaka. International Journal of Environmental Science and Development, 6(11), 811.

Umair, S., Björklund, A., \& Petersen, E. E. (2015). Social impact assessment of informal recycling of electronic ICT waste in Pakistan using UNEP SETAC guidelines. Resources, Conservation and Recycling, 95, 46-57. 
United Nations - International Solid Waste Association (2020). The Global E-Waste Monitor 2020. ISWA. ISWA: The Global E-Waste Monitor 2020

Vats, M. C., \& Singh, S. K. (2014). Status of e-waste in India-A review. transportation, 3(10).

Vincent, Z. (2021). Sparking Awareness in Lincoln Electronic Waste Trends and Habits: A Student Behavioral Analysis.

Wang, B., Ren, C., Dong, X., Zhang, B., \& Wang, Z. (2019). Determinants shaping willingness towards online recycling behaviour: An empirical study of household e-waste recycling in China. Resources, Conservation and Recycling, 143, 218-225.

Wang, Z., Guo, D., \& Wang, X. (2016). Determinants of residents' e-waste recycling behaviour intentions: evidence from China. Journal of cleaner production, 137, 850-860.

Wang, Z., Zhang, B., Yin, J., \& Zhang, X. (2011). Willingness and behavior towards e-waste recycling for residents in Beijing city, China. Journal of Cleaner Production, 19(9-10), 977-984.

Wath, S. B., Vaidya, A. N., Dutt, P. S., \& Chakrabarti, T. (2010). A roadmap for development of sustainable E-waste management system in India. Science of the Total Environment, 409(1), 19-32.

Wei, L., \& Liu, Y. (2012). Present status of e-waste disposal and recycling in China. Procedia Environmental Sciences, 16, 506-514.

Widmer, R., Oswald-Krapf, H., Sinha-Khetriwal, D., Schnellmann, M., \& Böni, H. (2005). Global perspectives on e-waste. Environmental impact assessment review, 25(5), 436-458.

Wolf, S. (1986). Self-interest and interest in selves. Ethics, 96(4), 704-720.

Xu, X., Yang, H., Chen, A., Zhou, Y., Wu, K., Liu, J., ... \& Huo, X. (2012). Birth outcomes related to informal ewaste recycling in Guiyu, China. Reproductive Toxicology, 33(1), 94-98.

Yang, W. D., Sun, Q., \& Ni, H. G. (2021). Cost-benefit analysis of metal recovery from e-waste: Implications for international policy. Waste Management, 123, 42-47.

Yin, R. (2003). Case study research: Design and methods (3rd ed.). Thousand Oaks, CA: Sage.

Zhang, L., Pradeep, T., Licence, P., Subramaniam, B., \& Allen, D. T. (2021). ACS Sustainable Chemistry \& Engineering Welcomes Manuscripts on Advanced E-Waste Recycling.

\section{Tables}

Table 1a: Demographics 




Table Source: Authors developed this from the collected data.

Table 2b: Demographics

\begin{tabular}{|c|c|c|c|c|c|c|c|c|c|}
\hline \multirow[t]{2}{*}{$\begin{array}{l}\text { S. } \\
\text { No. }\end{array}$} & \multirow[t]{2}{*}{ Specialization } & \multirow[t]{2}{*}{ Participants } & \multicolumn{2}{|c|}{$\begin{array}{l}\text { Laptops in } \\
\text { Possession }\end{array}$} & \multicolumn{2}{|c|}{$\begin{array}{c}\text { Cellphones in } \\
\text { Possession }\end{array}$} & \multicolumn{2}{|c|}{$\begin{array}{c}\text { PCs in } \\
\text { Possession }\end{array}$} & \multirow[t]{2}{*}{ Total } \\
\hline & & & Work & $\begin{array}{l}\text { Not- } \\
\text { work }\end{array}$ & Work & $\begin{array}{l}\text { Not- } \\
\text { work }\end{array}$ & Work & $\begin{array}{l}\text { Not- } \\
\text { work }\end{array}$ & \\
\hline 1 & $\mathrm{EE}$ & 8 & 9 & 3 & 13 & 4 & 1 & 5 & 35 \\
\hline 2 & CS & 6 & 8 & 3 & 10 & 3 & 2 & 4 & 30 \\
\hline 3 & $\begin{array}{l}\text { Accounting \& } \\
\text { Finance }\end{array}$ & 1 & 1 & 0 & 1 & 1 & 0 & 1 & 4 \\
\hline 4 & Agribusiness & 5 & 6 & 2 & 5 & 7 & 0 & 1 & 21 \\
\hline 5 & $\begin{array}{l}\text { Business } \\
\text { Administration }\end{array}$ & 6 & 6 & 1 & 6 & 3 & 1 & 1 & 18 \\
\hline 6 & Education & 1 & 1 & 0 & 1 & 0 & 0 & 0 & 2 \\
\hline 7 & Finance & 6 & 6 & 2 & 6 & 1 & 0 & 2 & 17 \\
\hline 8 & HRM & 1 & 1 & 1 & 1 & 2 & 0 & 1 & 6 \\
\hline & & 34 & 34 & 38 & 12 & 43 & 21 & 4 & 15 \\
\hline
\end{tabular}

Here EE, CS, and HRM refer to Electrical and Electronic Engineering, Computer Science, and Human Resource Management, respectively.

Table Source: Authors developed this from the collected data.

\section{Figures}




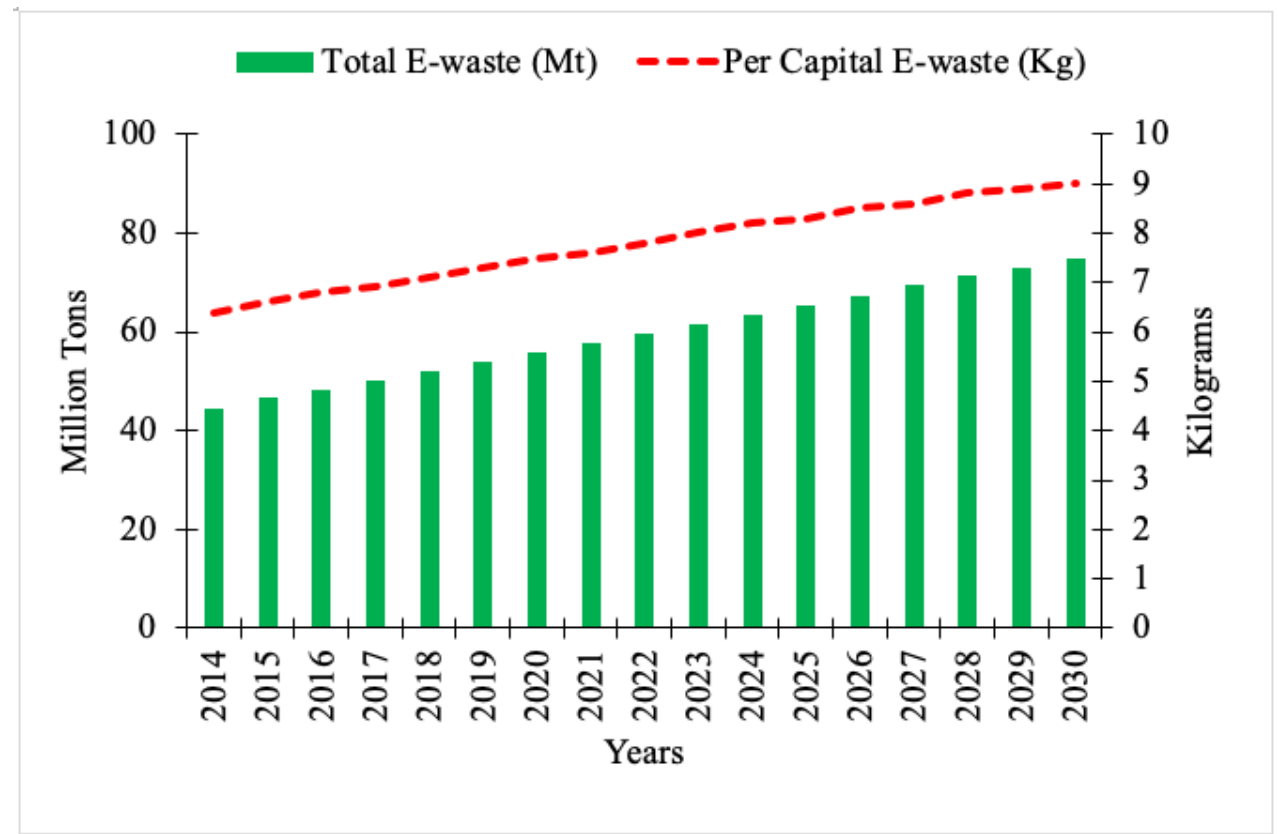

Figure 1a: Global E-waste Generated

Source: Forti et al. (2020).

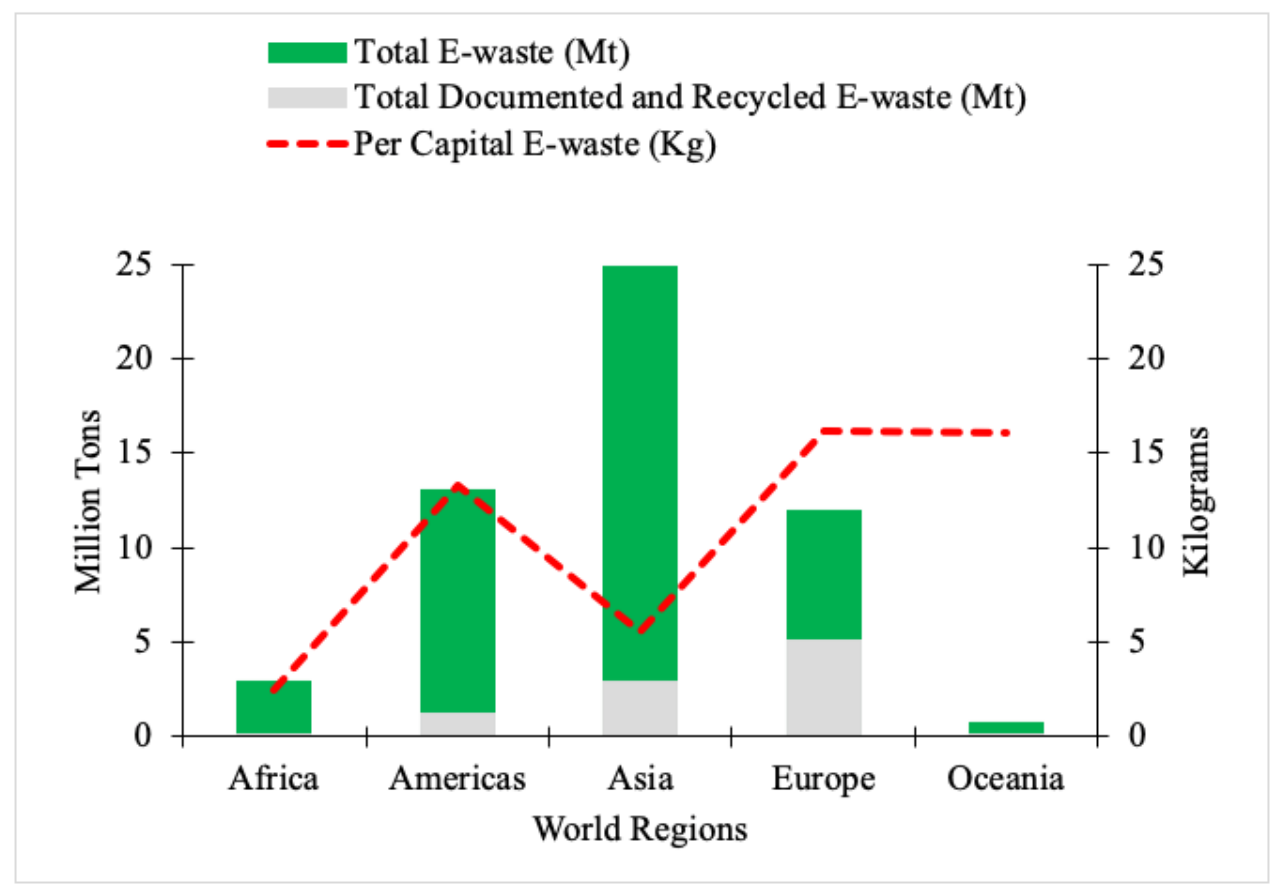

Figure 1b: Regional E-waste Generated

Source: Forti et al. (2020); UN-ISWA (2020)

Figure 1

1a: Global E-waste Generated

Source: Forti et al. (2020).

1b: Regional E-waste Generated 
Source: Forti et al. (2020); UN-ISWA (2020)

Figure 2

Proposed Conceptual Framework Based on the Data

Source: Authors generated from the data

\section{Supplementary Files}

This is a list of supplementary files associated with this preprint. Click to download.

- APPENDIX.docx 